\title{
Predominance of syntrophic bacteria, Methanosaeta and Methanoculleus in a two-stage up-flow anaerobic sludge blanket reactor treating coffee processing wastewater at high organic loading rate
}

\author{
Wilmar Alirio Botello Suárez ${ }^{\mathrm{a}, \mathrm{b}}$, Juliana da Silva Vantini ${ }^{\mathrm{a}, \mathrm{c}}$, Rose Maria Duda ${ }^{\mathrm{d}}$, \\ Poliana Fernanda Giachetto ${ }^{\mathrm{e}}$, Leandro Carrijo Cintra ${ }^{\mathrm{e}}$, Maria Inês Tiraboschi Ferro ${ }^{\mathrm{a}, \mathrm{c}}$, \\ Roberto Alves de Oliveira ${ }^{\mathrm{a}, \mathrm{b}, *}$ \\ a Post-Graduate Program in Agricultural and Livestock Microbiology, São Paulo State University (UNESP), School of Agricultural and Veterinarian Sciences, Jaboticabal, \\ SP, Brazil \\ ${ }^{\mathbf{b}}$ Laboratory of Environmental Sanitation, Department of Rural Engineering, São Paulo State University (UNESP), School of Agricultural and Veterinarian Sciences, \\ Jaboticabal, SP, Brazil \\ ${ }^{\mathrm{c}}$ Laboratory of Biochemistry and Molecular Biology, Department of Technology, São Paulo State University (UNESP), School of Agricultural and Veterinarian Sciences, \\ Jaboticabal, SP, Brazil \\ d Faculty of Technology, Jaboticabal, SP, Brazil

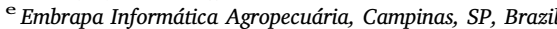

\section{A R T I C L E I N F O}

\section{Keywords:}

Anaerobic digestion

Biogas

Methanogenic archaea

Metagenomics of anaerobic sludge

Pollutant removal

\begin{abstract}
A B S T R A C T
The effect of the organic loading rate (OLR) on the performance and microbial composition of a two-stage UASB system treating coffee processing wastewater was assessed. The system was operated with OLR up to $18.2 \mathrm{~g}$ COD $(\mathrm{Ld})^{-1}$ and effluent recirculation. Methane production and effluent characteristics were monitored. The microbial composition was examined through next-generation sequencing and qPCR from the anaerobic sludge of the first reactor (R1) operated at low and high OLR. The system showed operational stability, obtaining a maximum methane production of $2.2 \mathrm{~L} \mathrm{CH}_{4}(\mathrm{~L} \mathrm{~d})^{-1}$, with a removal efficiency of COD and phenolic compounds of 84 and 73\%, respectively. The performance of R1 at high OLR in steady conditions was associated with an appropriate proportion of nutrients (particularly Fe) and a marked increase of the syntrophic bacteria Syntrophus and Candidatus Cloacimonas, and acetoclastic and hydrogenotrophic methanogens, mainly Methanosaeta, Methanoculleus, Methanobacterium and Methanomassiliicoccus.
\end{abstract}

\section{Introduction}

Coffee agro-industry represents one of the leading economic activities in tropical developing countries (FAO, 2015). Currently, about $50 \%$ of the coffee production worldwide ( 4.3 million tons) is concentrated in Brazil, Vietnam and Colombia (ICO, 2018). To improve the quality of the final product, the leading producing countries have increasingly adopted the wet coffee processing as a post-harvest procedure. This method requires about $7.5 \mathrm{~m}^{3}$ of water to process 1 ton of coffee cherries, generating a significant volume of coffee processing wastewater (CPW), rich in organic matter represented mainly by easily fermentable sugars (Alves et al., 2017). Moreover, CPW contains nitrogen, phosphorus, and toxic chemicals including tannins, caffeine and polyphenols (Rattan et al., 2015), constituting a serious threat to the ecosystems in producing areas, unless treated or appropriately reused.

It has been demonstrated that CPW can be stabilized by anaerobic digestion, a process in which a highly adapted microbiota produce biogas containing methane (Beyene et al., 2014). The application of the up-flow anaerobic sludge blanket (UASB) or related technologies constitutes a promising strategy for this purpose, which can be submitted to high organic loading rates (OLRs) to enhance the energy recovery. However, three major drawbacks should be attended to optimize this process: i) the high content of easily fermentable sugars and low alkalinity of CPW, which can produce an acid accumulation that inhibits the methanogenic activity; ii) the reduction of the effluent quality by application of high OLR and iii) the lack of knowledge of the associated microbiota, since previous works have only focused on operational aspects or analysis limited to study of cultivable microorganisms (Pires

\footnotetext{
* Corresponding author at: Post-Graduate Program in Agricultural and Livestock Microbiology, São Paulo State University (UNESP), School of Agricultural and Veterinarian Sciences, Jaboticabal, SP, Brazil.

E-mail address: oliveira@fcav.unesp.br (R.A. de Oliveira).
} 
et al., 2017; Villa-Montoya et al., 2017).

Despite the implementation of the single stage UASB, expanded granular sludge bed, anaerobic fixed bed and up-flow anaerobic hybrid systems, the first two issues aforementioned have not been satisfactorily resolved (Cruz-Salomón et al., 2017; Fia et al., 2012; Guardia-Puebla et al., 2014; Selvamurugan et al., 2010). In this regard, diverse studies have attempted to separate the acidogenic and methanogenic phases in independent reactors (Guardia-Puebla et al. 2014; Jung et al., 2012). However, this approach seems impractical in technical terms, as it requires greater process control, increases the cost of investment and operation for an eventual application in producing regions.

Since the CPW is easily hydrolysable, we consider that the application of two UASB reactors installed in series (two-stage UASB system), in which proper operational conditions (i.e. alkalinity source by effluent recirculation and successive OLR increase) could allow a high methane production in the first reactor, maintaining a stable pollutant removal efficiency favored by the second. In addition, the system operation could be eventually optimized by an improved understanding of the microbial composition and its adaptation in response to control parameters such as OLR increase. In this regard, molecular procedures such as next generation sequencing (NGS) or quantification of specific microbial groups by quantitative real-time PCR (qPCR) constitute excellent approaches to unravel phylogenetic and functional aspects about prevalent microbial communities in anaerobic reactors (Cai et al., 2016; Delforno et al., 2017; Kim et al., 2013).

Therefore, the aim of the present study was to assess the effects of the OLR on the performance and microbial composition of a two-stage UASB system treating CPW. For this, the OLR was gradually increased from 6.1 to $18.2 \mathrm{~g}$ COD $(\mathrm{Ld})^{-1}$, controlling the influent alkalinity by effluent recirculation. The system performance was assessed considering the effluent characteristics, nutrients proportion and sludge development. To gain valuable insight on the microbial community composition associated with this process, we analyze the sludge of the first reactor by NGS and qPCR in response to low and high OLR conditions.

\section{Material and methods}

\subsection{Configuration of the two-stage UASB system}

The system was composed of two UASB reactors in series (R1 and R2) (Fig. 1), with working volumes of $20 \mathrm{~L}$ and $10 \mathrm{~L}$, respectively. The characteristics of the reactors used had been previously described

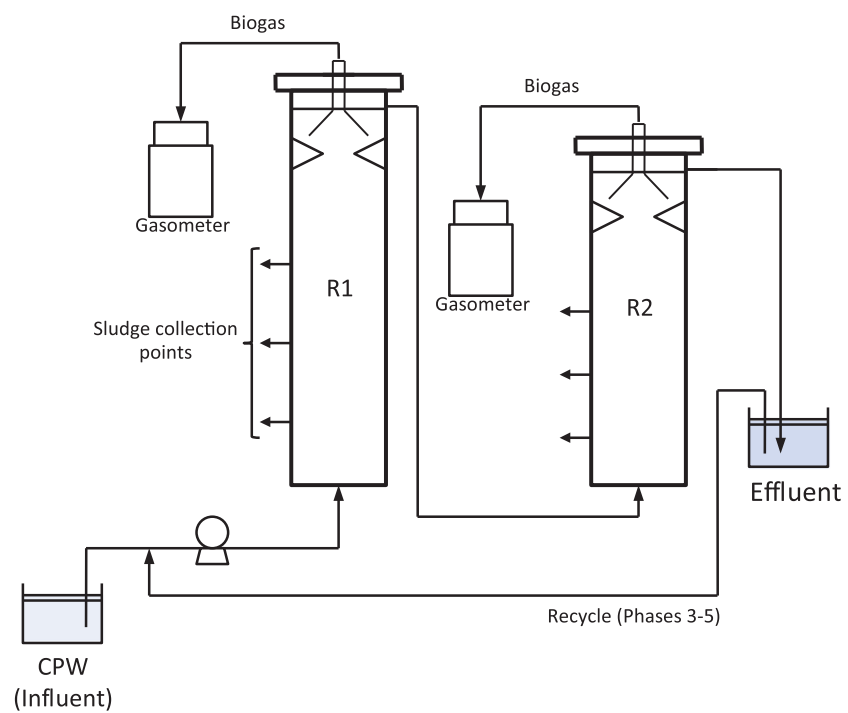

Fig. 1. Configuration of the two-stage UASB system (R1 and R2) for CPW treatment.
(Bruno and Oliveira, 2013). This configuration was established in order to reach stabilization of easily biodegradable organic matter in the first reactor, enhancing the rate of organic conversion, and subsequently carrying out the degradation of persistent chemical oxygen demand (COD) and remaining soluble compounds in the second reactor, thus attempting to ensure a high removal efficiency at high OLR. The UASB reactors were already in operation, at OLR of $6.0 \mathrm{~g} \mathrm{COD}(\mathrm{Ld})^{-1}$ and the total and volatile solids (TS, VS) of the sludge were respectively $\left(\mathrm{g} \mathrm{L}^{-1}\right)$ : 46.2 and 36.8 (R1), and 36.6 and 30.5 (R2). The operation was realized for 365 days, increasing the OLR when stability conditions were achieved: constant biogas production and COD removal, with variation coefficients minor than $20 \%$, establishing five operational phases (Table 1).

\subsection{Influent characteristics}

The influent of the UASB system was constituted by CPW collected in a producing farm in Pedregulho, in the state of São Paulo State (Brazil) (latitude: $20^{\circ} 15^{\prime} 27^{\prime \prime} \mathrm{S}$, longitude: $47^{\circ} 28^{\prime} 39^{\prime \prime} \mathrm{W}$ ), during the harvest period (April-July of 2015) and stored at $-5^{\circ} \mathrm{C}$. Due to large amounts of substrate required, continuous operation was ensured through the preparation of simulated CPW, as described previously by Bruno and Oliveira (2013). Before its use, physicochemical characteristics of the raw $\mathrm{CPW}$ were determined. Then, the substrate was diluted to keep the COD concentration as needed to reach the adequate OLR. The $\mathrm{pH}$ of the influent was adjusted to optimal levels for anaerobic treatment $(7.0 \pm 0.2)$ using lime $\left(\mathrm{Ca}(\mathrm{OH})_{2}\right)$ and effluent recirculation. The influent characteristics are shown in Table 1.

\subsection{Analytical methods}

System performance was evaluated using physicochemical determinations on influents and effluents twice a week. The samples of influent (inlet of R1) and effluents (output of R1 and R2) were composed from single samples of $0.2 \mathrm{~L}$. Parameters TS, VS, COD, pH, total, partial, and intermediate alkalinity (TA, PA, and IA), total volatile acids (VFA), total ammonia nitrogen (TAN), total Kjeldahl nitrogen (TKN), and total phenol content (TPC), and were measured as stated in the methodologies described in APHA (2005), Ripley et al. (1986), DiLallo and Albertson (1961) and Singleton et al. (1998). The concentration of total phosphorus (TP), $\mathrm{K}, \mathrm{Mg}$, $\mathrm{Ca}$ and the trace elements iron (Fe), zinc $(\mathrm{Zn})$, copper $(\mathrm{Cu})$ and manganese $(\mathrm{Mn})$ was determined weekly after acid (nitric-perchloric) digestion of the sample and measured by atomic absorption spectrophotometer, as described by APHA (2005). The volume of biogas produced was measured daily in gasometers, and biogas composition was analyzed weekly by gas chromatography (APHA, 2005). The results of the methane production were reported at standard temperature and pressure (STP. $101.325 \mathrm{kPa}$. 273.15 K). Samples of sludge $(50 \mathrm{~mL})$ were collected at intervals of 30 days from different sludge collection points (Fig. 1), to measure the TS and VS (APHA, 2005). The distances from the base of each reactor to the corresponding sampling points were 15,45 and $65 \mathrm{~cm}$ in $\mathrm{R} 1$ and 18,38 and $58 \mathrm{~cm}$ in R2, conforming three levels along of the digestion compartments: bottom, middle and top, respectively.

\subsection{Theoretical calculations and statistical analysis}

The optimum ranges of essential elements for the anaerobic digestion were estimated according to Wu et al. (2016) using the composition of major and trace elements of methanogenic archaea determined by Scherer et al. (1983). Optimal levels calculated were (mg element (mg COD removed) ${ }^{-1}$ ): 3.9-575.1 (K), 1.4-56.5 (Mg), 1.3-4.5 (Ca), 1.1-30.1 (Fe), 0.1-6.6 (Zn), 0.02-1.69 (Cu) and 0.04-0.75 Mn. For macronutrients, a theoretical optimal ratio of COD:N:P of 350:5:1 was considered (Chernicharo, 2007). For the statistical analysis of the removal efficiencies, an analysis of variance was performed using the 
Table 1

Operational conditions of the two-stage UASB system and influent composition.

\begin{tabular}{|c|c|c|c|c|c|}
\hline & Phase 1 & Phase 2 & Phase 3 & Phase 4 & Phase 5 \\
\hline \multicolumn{6}{|l|}{ Operational conditions } \\
\hline OLR R1 (g COD $(\mathrm{Ld})^{-1}$ ) & $6.1 \pm 0.4$ & $7.0 \pm 0.7$ & $10.1 \pm 1.2$ & $15.0 \pm 2.0$ & $18.2 \pm 1.7$ \\
\hline OLR R2 (g COD $\left.(\mathrm{Ld})^{-1}\right)$ & $1.6 \pm 0.4$ & $2.1 \pm 0.5$ & $2.5 \pm 0.9$ & $8.6 \pm 1.1$ & $9.5 \pm 0.8$ \\
\hline HRT R1 (h) & 60 & 60 & 60 & 30 & 30 \\
\hline HRT R2 (h) & 30 & 30 & 30 & 15 & 15 \\
\hline SLR R1 $\left(\mathrm{g}\right.$ COD $(\mathrm{g} \mathrm{VS} \mathrm{d})^{-1}$ & 0.26 & 0.23 & 0.21 & 0.16 & 0.18 \\
\hline SLR R2 $\left(\mathrm{g}\right.$ COD $(\mathrm{g} \text { VS d })^{-1}$ & 0.09 & 0.09 & 0.11 & 0.23 & 0.37 \\
\hline CPW: Effluent ratio & $1: 0$ & $1: 0$ & $4: 1$ & $2: 1$ & $3: 1$ \\
\hline $\mathrm{Ca}(\mathrm{OH})_{2}\left(\mathrm{~g} \mathrm{~L}^{-1}\right)$ & $4.4 \pm 2.1$ & $4.7 \pm 1.9$ & $3.2 \pm 1.7$ & $2.4 \pm 1.0$ & $2.8 \pm 1.6$ \\
\hline Temperature $\left({ }^{\circ} \mathrm{C}\right)$ & $24.4 \pm 2.1$ & $20.7 \pm 2.0$ & $21.5 \pm 3.1$ & $25.7 \pm 2.6$ & $24.3 \pm 1.6$ \\
\hline Days in operation & 95 & 90 & 60 & 60 & 60 \\
\hline \multicolumn{6}{|l|}{ Influent characteristics } \\
\hline $\mathrm{pH}$ & $7.2 \pm 0.3$ & $7.3 \pm 0.2$ & $7.3 \pm 0.3$ & $7.2 \pm 0.3$ & $7.2 \pm 0.4$ \\
\hline $\mathrm{PA}\left(\mathrm{mg} \mathrm{CaCO} \mathrm{L}^{-1}\right)$ & $785 \pm 382$ & $1138 \pm 585$ & $943 \pm 204$ & $1495 \pm 546$ & $1810 \pm 589$ \\
\hline $\mathrm{VFA}\left(\mathrm{mg} \mathrm{L}^{-1}\right)$ & $1497 \pm 580$ & $2741 \pm 868$ & $3413 \pm 621$ & $3650 \pm 969$ & $3923 \pm 1314$ \\
\hline $\mathrm{TS}\left(\mathrm{mg} \mathrm{L}^{-1}\right)$ & $9615 \pm 2310$ & $12185 \pm 3837$ & $17016 \pm 5577$ & $15142 \pm 5237$ & $20270 \pm 6167$ \\
\hline VS $\left(\mathrm{mg} \mathrm{L}^{-1}\right)$ & $7197 \pm 2595$ & $7864 \pm 3065$ & $13326 \pm 5644$ & $9028 \pm 4549$ & $11948 \pm 1633$ \\
\hline $\operatorname{COD}\left(\mathrm{mg} \mathrm{L}^{-1}\right)$ & $15378 \pm 548$ & $17458 \pm 1665$ & $24945 \pm 3948$ & $18879 \pm 3107$ & $22489 \pm 2242$ \\
\hline TAN $\left(\mathrm{mg} \mathrm{L}^{-1}\right)$ & $139 \pm 51$ & $166 \pm 92$ & $91 \pm 29$ & $243 \pm 91$ & $246 \pm 63$ \\
\hline $\mathrm{TKN}\left(\mathrm{mg} \mathrm{L}^{-1}\right)$ & $422 \pm 154$ & $350 \pm 127$ & $446 \pm 38$ & $750 \pm 176$ & $656 \pm 93$ \\
\hline $\mathrm{TP}\left(\mathrm{mg} \mathrm{L}^{-1}\right)$ & $160 \pm 81$ & $158 \pm 46$ & $91 \pm 7$ & $81 \pm 6$ & $101 \pm 18$ \\
\hline $\mathrm{TPC}\left(\mathrm{mg} \mathrm{L}^{-1}\right)$ & $374.0 \pm 97.4$ & $363 \pm 124$ & $517 \pm 121$ & $673 \pm 200$ & $627 \pm 141$ \\
\hline
\end{tabular}

Means values followed by standard deviations. OLR: Organic loading rate; HRT: Hydraulic retention time; SLR: Sludge loading rate; TVA: Total volatile acids; PA: Partial alkalinity; TS: Total solids; VS: Volatile solids; COD: Chemical oxygen demand; TAN: Total ammonia nitrogen; TKN: Total Kjeldahl nitrogen; TP: Total phosphorous; TPC: Total phenol content.

Tukey test. Linear association between some critical variables was performed using the Pearson correlation coefficient (R), and its statistical significance (p). The statistical data analysis was carried out using R software (version 3.1.3).

\subsection{Microbial community composition}

\subsubsection{Sampling and genomic DNA extraction}

Sludge samples were collected in operational stability conditions from three different levels of R1 (Fig. 1), at 90 and 335 days of operation, corresponding to low and high OLR: 6.1 and $18.2 \mathrm{~g}$ COD $(\mathrm{Ld})^{-1}$, respectively. The VS concentrations $\left(\mathrm{g} \mathrm{L}^{-1}\right)$ for the bottom, middle and top levels were respectively: 46.4, 39.2 and 34.8 (low OLR), and 86.4, 66.5 and 40.0 (high OLR). Individual sludge samples of each level and a composite sludge sample from the three levels for each condition were used. The collected sludge was homogenized and centrifuged at $10.000 \times g$ for $10 \mathrm{~min}$. After removing the supernatant, the resultant pellets $(0.25-0.30 \mathrm{~g})$ were used for the following steps. Total DNA was extracted using the QIAGEN's DNeasy PowerSoil Kit - Sil Life. We used Nanodrop ND-1000 (Thermo Scientific, Wilmington, DE, USA) and visualization on $1 \%(\mathrm{w} / \mathrm{v})$ agarose gel with $1 \times$ TAE buffer to assess the quality and integrity, respectively. The quantification was assessed using the Qubit dsDNA HS Assay Kit (Invitrogen, Carlsbad, California, USA), following the manufacturer's instructions. The genomic DNA was stored at $-20{ }^{\circ} \mathrm{C}$ until the assays were conducted.

\subsubsection{Sequencing and data analysis}

The microbial composition was examined from composed sludge samples of each collection point of R1 (Fig. 1) considering the two OLR conditions. DNA libraries for NGS were prepared using the TruSeq Nano DNA LT Sample Prep Kit (Illumina, USA), following the manufacturer's instructions. The samples were sequenced on a single lane on an Illumina HiSeq 2500 (Illumina, San Diego, CA) in paired-end mode $(2 \times 100 \mathrm{bp})$. For the bioinformatic analysis, the raw data were initially submitted to a quality control using the SeqClean software (v1.9.10), and then low-quality regions were trimmed. From this point only reads above $80 \mathrm{pb}$ were considered. A quality report was generated using FastQC (v0.11.5, Babraham Institute, UK). Subsequently, human contaminants were removed by aligning sequences on hg38 human reference genome using the FR-Hit (v0.7) software (Niu et al., 2011). Afterward, sequences were masked for rRNA and tRNA using the rnahmm3.py (v3.0) and the tRNAscan-SE (v1.3.1) software respectively. The reads were identified using NR database as reference with the Diamond (v0.7.12.61) software for alignment. MEGAN (v6.11.1) was used for subsampling taxonomic classification by the lowest common ancestor (LCA) algorithm (Huson et al., 2007). The metagenome was assembled using the IDBA-UD (v1.1.1) software (Peng et al., 2012).

\subsubsection{Real-time quantitative PCR analyses}

Real-time quantitative PCR (qPCR) was conducted with DNA samples isolated from the sludge from three different collection points (Fig. 1) of the digestion compartment of R1 (bottom, middle and top) at low and high OLR. The domains Bacteria and Archaea, and the methanogenic groups Methanobacteriales, Methanomicrobiales, Methanosarcinales, Methanosarcinaceae and Methanosaetaceae were quantified using specific primers for the 16S rDNA region, described by Lee et al. (1996) and Song et al. (2010). A detailed description of the qPCR analysis performed in this study can be found in Duda et al. (2015). The reactions were conducted in the Applied Biosystems 7500 Real-Time PCR apparatus and included 6.25 $\mu \mathrm{L}$ of Power SYBR Green ${ }^{\circledR}$ MasterMix (Applied Biosystems), primers at different concentrations, $10 \mathrm{ng}$ of metagenomic DNA and ultrapure water to bring the reaction volume to $12.5 \mu \mathrm{L}$. The cycle consisted in $2 \mathrm{~min}$ at $50^{\circ} \mathrm{C} ; 10 \mathrm{~min}$ at $95^{\circ} \mathrm{C}$; and 40 cycles at $95^{\circ} \mathrm{C}$ for $15 \mathrm{~s}, 1 \mathrm{~min}$ at specific annealing temperatures and $30 \mathrm{~s}$ at $78{ }^{\circ} \mathrm{C}$. To obtain a dissociation curve of the reaction products a step with increasing temperature $\left(60-95^{\circ} \mathrm{C}\right)$ was applied. The copy number of each sample was determined by serial dilution of the standard curve from a linearized plasmid containing the 16S rDNA regions, $3 \times 10^{8}-3 \times 10^{2} \quad(1: 10)$, except the order Methanobacteriales $\left(3 \times 10^{8}-2 \times 10^{4}(1: 5)\right)$. The values $\mathrm{Ct}$ of the samples were compared to standard curves to determine the number of copies 16S rDNA per volatile solids in the digestion compartment of R1.

\section{Results and discussion}

\subsection{Stability of UASB reactors at increasing OLR}

The two-stage UASB system showed a suitable buffer capacity 


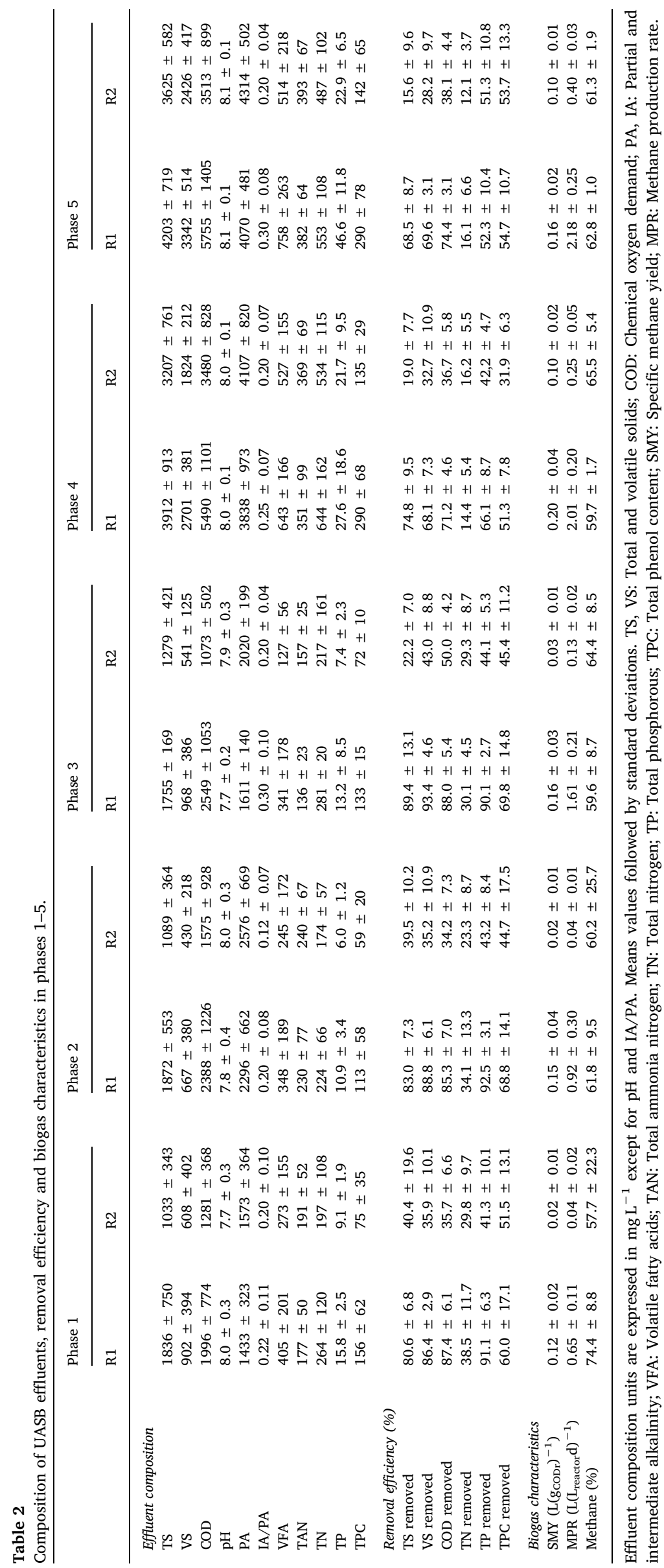


during the experimental period. The partial alkalinity (PA) in both, R1 and R2, was enough to neutralize the acids formed in the process, without causing a substantial drop in $\mathrm{pH}$ (Table 2). Although effluent recirculation did not completely reduced the alkalinizing use, allowed the increase of the PA in the influent from phase 3, and even at highest OLR applied the PA values reached mean levels above $4000 \mathrm{mg} \mathrm{L}^{-1}$ in the effluents of R1 and R2 (Table 2). The reduction of alkalinity requirements for the substrate in the anaerobic digestion process is a useful feature of effluent recirculation strategy, which allows making a more economically viable operation. Besides, this alternative may also be used to maintain appropriate OLR in the system, especially with substrates with high concentrations of organic matter (Barros et al., 2017). In this study, we have found that the effluent recirculation is an effective method to maintain the buffer capacity in a two-stage UASB system when a broad range of OLR is applied during the CPW treatment.

Anaerobic digestion is considered to be stable at IA/PA ratio less than 0.3 (Ripley et al., 1986). Despite the increase in VFA concentration, IA/PA ratio was maintained within acceptable levels, with similar values for all phases evaluated in each reactor (Table 2). This indicates operational stability (with a low risk of acidification), including phases 4 and 5, which had the highest OLR and the lowest hydraulic retention times (HRT). Consequently, alkalinity supplementation by effluent recirculation allowed generating fair conditions for anaerobic digestion.

TAN concentrations were greater in phases 4 and 5, evidencing an increase up to $50 \%$ with an increase in the OLR from 10.1 to $14.4 \mathrm{~g}$ COD $(\mathrm{Ld})^{-1}$ (Table 2). This difference is possibly caused by increase of TAN concentration in the influent of the UASB system (Table 1), effluent recirculation, and major protein hydrolysis and ammonium production. Although the TAN may cause an increase in the $\mathrm{pH}$ value, counteracting its reduction by the acidification step, it may cause an adverse effect on anaerobic digesters, usually between 1300 and $6000 \mathrm{mg} \mathrm{L}^{-1}$ (Yenigün and Demirel, 2013). Accordingly, concentrations of TAN were found under tolerable levels in all phases tested.

\subsection{Effect of OLR on COD removal and methane production}

A high removal efficiency of organic matter was observed throughout the experimental period, mainly in phases 1-3 (OLR:

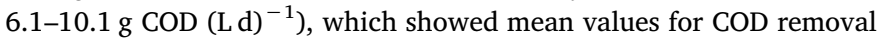
up to $88 \%$ in R1 and $50 \%$ in R2, with a maximum global efficiency of $96 \%$ (Fig. 2a). These results were similar with the previously described removal efficiencies using high-rate anaerobic reactors treating $\mathrm{CPW}$ at low OLRs (Bruno and Oliveira, 2013; Jung et al., 2012; Selvamurugan et al., 2010). The stability of the anaerobic reactors was not considerably affected by the HRT reduction from $90 \mathrm{~h}$ to $45 \mathrm{~h}$, and subsequent OLR increase above $15 \mathrm{~g}$ COD $(\mathrm{Ld})^{-1}$.

At high OLR the system showed a removal efficiency of $84 \%$. This suggests an effective organic matter removal even under this condition, favored by a stable performance. In addition, since COD removal in R1 in this condition was only $74 \%$ (Table 2 ), the operation of R2 proved to be effective in maintaining high removal efficiency in the system. Thus, the application of UASB reactors in series was adequate to the initial purpose to reach a high OLR with effective removal efficiency. In addition, a positive correlation between the OLR applied and organic load removed in the two reactors (Fig. 3) was found, with significant Pearson's correlation coefficients $(\mathrm{p}<0.001)$. Therefore, the reduction of COD removal efficiencies was also countered with higher rate of organic load removal.

Even though the highest COD removal efficiencies in R1 (approximately 2-folds greater than R2 (Fig. 2a), may be influenced by a major HRT and highest substrate availability, it seems that, as expected, the application of high OLR in R1 induce a positive effect in R2, improving its contribution to the overall efficiency of the system. This is particularly evident in phase 3 (at OLR of $2.5 \mathrm{~g} \mathrm{COD} \mathrm{(Ld)})^{-1}$ in R2), where the COD removal efficiency in this reactor was $16 \%$ higher than the previous phase (Table 2). Accordingly, the observed increment of the COD removal in $\mathrm{R} 2$ could be attributed to the increase of organic matter concentration in the influent. Consequently, higher amounts of precursors for the anaerobic digestion in $\mathrm{R} 1$ provided larger concentration of remaining biodegradable COD for R2.

The reactors presented a significant difference in terms of removal of organic load, even at similar OLR (Fig. 3). This can be explained by the high consumption of VFAs in the methanogenic step of R1. As is well known, the VFAs are degraded by syntrophic associations of anaerobic bacteria and methanogenic archaea to acetate, $\mathrm{CO}_{2}, \mathrm{H}_{2}$ and formate (Stams et al., 2012). The high concentration of VFAs in the influent of R1, which ranges between 1417 and $3923 \mathrm{mg} \mathrm{L}^{-1}$ (Table 1), suggests that in this reactor the anaerobic microbiota degraded directly a significant fraction of the COD. Meanwhile, VFAs in the R2 influent ranged between 341 and $758 \mathrm{mg} \mathrm{L}^{-1}$ (Table 2), representing a low fraction of total COD of the influent. Therefore, in this reactor the COD removal depends mainly on the degradation of recalcitrant compounds.

$\mathrm{CPW}$ is composed by quickly fermenting sugars, and also presents different constituents that become particularly difficult to degrade, coming from the mucilage layer, mainly proteins, sugars, and pectins (Rattan et al., 2015). Thus, it is probable that the easily degraded organic matter serves as a substrate for metabolic and microbial growth activities in R1, and more complex constituents persist in the effluent. In this way it is incorporated to R2, which can slow down the degradation process in this reactor and as observed, generate lower rates of organic load removal.

The highest methane production rates (MPR) were obtained after 306 days of operation, corresponding to OLR above $18 \mathrm{~g} \mathrm{COD}(\mathrm{L} \mathrm{d})^{-1}$ in R1 (phase 5) (Fig. 2b-c). In this condition, the mean value of MPR in R1 $\left(2.18 \mathrm{~L} \mathrm{CH}_{4}(\mathrm{~L} \mathrm{~d})^{-1}\right.$ ) was 5.5 times greater in relation to R2 (Table 2), and 3 times greater in relation to phase 1 . Accordingly, a strong Pearson's correlation $(\mathrm{p}<0.001)$ was evidenced between MPR and OLR variables in both reactors, which indicate that gradual increase of the OLR allows a satisfactory methane production. These results were consistent with the highest levels of organic load removal observed in the same period and were higher with respect to those previously reported in anaerobic digestion systems treating CPW (Guardia-Puebla et al., 2014; Jung et al., 2012; Selvamurugan et al., 2010; VillaMontoya et al., 2017) due to the higher OLR reached.

The specific methane yield (SMY) calculated to each phase showed mean values ranged from 0.12 to $0.2 \mathrm{~L} \mathrm{CH}_{4}\left(\mathrm{~g} \mathrm{COD}_{\text {removed }}\right)^{-1}$ in $\mathrm{R} 1$, and 0.02 to $0.1 \mathrm{~L} \mathrm{CH}_{4}$ (g COD removed $^{-1}$ in R2 (Table 2). To obtain the overall specific methane yield of the reactors the methane production rate as a function of substrate consumption rate was plotted, obtaining determination coefficients $\left(\mathrm{R}^{2}\right)$ above 0.92 . Thus, SMY for the anaerobic reactors were 0.16 and $0.10 \mathrm{~L} \mathrm{CH}_{4}\left(\mathrm{~g} \mathrm{COD}_{\text {removed }}\right)^{-1}$ for $\mathrm{R} 1$ and $\mathrm{R} 2$, respectively. Theoretically, the maximum SMY that may be ob-

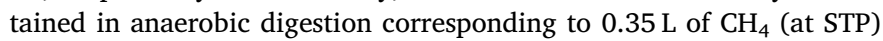
per $g$ of COD stabilized (McCarty, 1964). Thus, the overall SMY achieved in this study represent efficiencies of $46 \%$ (R1) and $26 \%$ (R2), obtaining the maximum efficiency in R1 in (phase 4), corresponding to $57 \%$ respected the theoretically estimated.

The levels of SMY obtained can be explained partly as a result of dissolution in the liquid phase and throw away with the final effluent. Besides, the use of lime as alkalinity source may lead to the precipitation of organic matter (Chen et al., 2008) and consequently part of the removed COD is not biologically degraded. Therefore, the values of SMY suggests that the process can be optimized through others strategies (i.e. operation at constant temperature. The high methane production and organics removal obtained suggest that the operation of the two-stage UASB system for treating CPW was effective, allowing the application of high OLR and maintaining a suitable removal efficiency of organic matter provided by the operation of R2. 


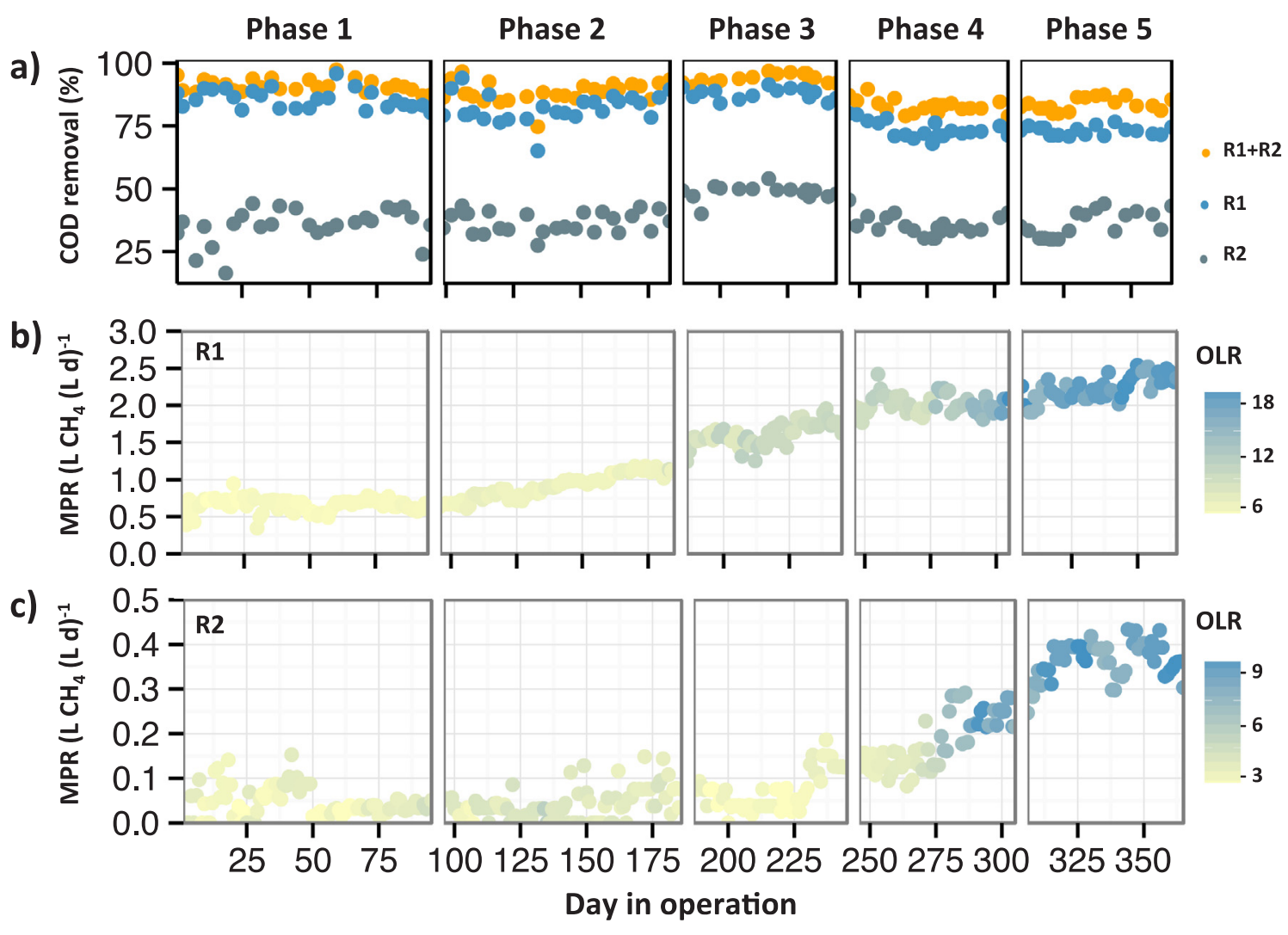

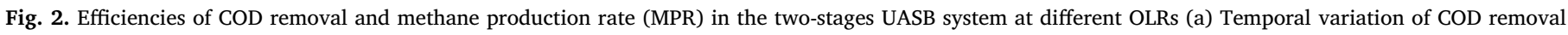
during the experimental period; (b) MPR in R1; (c) MPR in R2.

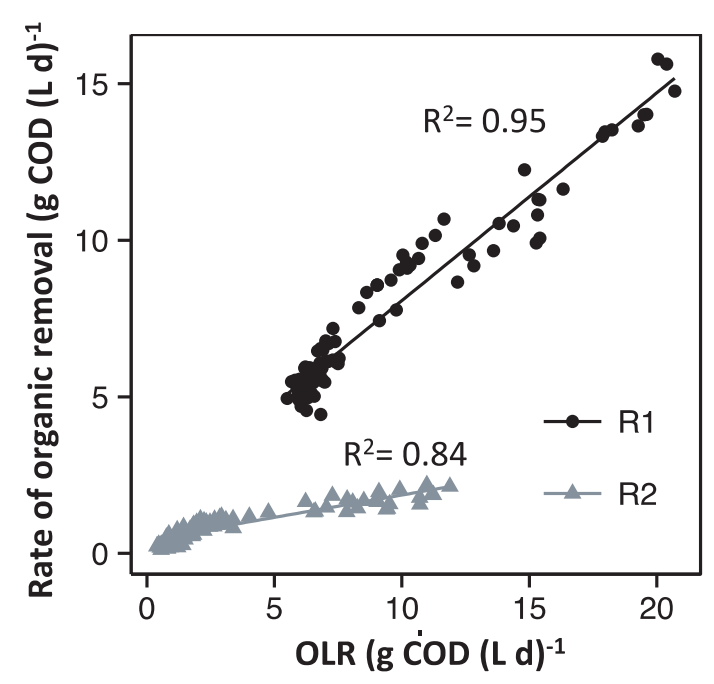

Fig. 3. Linear regression analysis for the correlation between the organic loading rate and rate of organic removal in R1 and R2.

\subsection{Pollutant removal efficiency at increasing $O L R$}

In order to establish the effectiveness of the serial configuration of UASB reactors at increasing OLRs concerning pollutant removal, we analyzed some environmental, well-known indicators of water quality related to the CPW characteristics. Thus, removal efficiencies for total nitrogen (TN), total phosphorus (TP), volatile solids (VS) and total phenol content (TPC) in R1, R2 and for the system (R1 + R2) were established for each phase analyzed (Table 2).
As expected, the highest removal levels were obtained at low OLRs

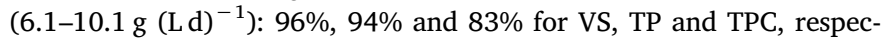
tively. In the majority of the parameters the increase of OLR to $18.2 \mathrm{~g}$ $(\mathrm{Ld})^{-1}$ and consequent decrease of HRT to $45 \mathrm{~h}$ induced a reduction of the removal efficiency (Table 2). However, except TN, the reactor R2 did not present significant variations along the increase of OLR ( $p<0.05$ ), enabling an increase of the efficiency of the system in such conditions. This observation underlines that, although R2 does not contribute substantially to methane production, it has a critical role in the stabilization of CPW regardless the OLR applied, generating a better-quality effluent.

TN removal was generally low in the two reactors, obtaining a maximum efficiency at low OLRs (about 55\%). This reduction may be associated mainly with the assimilation of organic nitrogen by the system microbiota. Otherwise, the levels of TP removal (mainly in phases 1-3) were probably induced by chemical precipitation phenomena, which can be attributed to the lime application in the influent. Hosni et al. (2008), working with synthetic wastewater showed that phosphorus precipitation is increased starting from molar ratios of $\mathrm{Ca}$ / $\mathrm{P}>0.3$. We determined the $\mathrm{Ca}$ and $\mathrm{P}$ concentrations in the influent, obtaining molar ratios of $\mathrm{Ca} / \mathrm{P}$ of $0.4-0.8$, which might suggest ideal conditions to phosphorous precipitation.

At high OLRs, the UASB system was particularly efficient in the removal of TPC (73\%) (Table 2). Several biochemical pathways have been described to explain the biodegradation of phenols under anaerobic conditions (Wirth et al., 2015), which lead to the generation of acetate that subsequently may be the substrate for acetotrophic methanogens. Therefore, the TPC removal observed in the UASB system indicates activity of phenol-degrading microorganisms, favored by the gradual OLR increase and possibly by the effluent recirculation, which allows the reincorporation of adapted microorganisms to the system. Apart from the high methane production, phase 5 showed removals 
efficiencies above $76 \%$ for COD, TP, and VS. In terms of biological degradation, there was also evidence of TPC reduction. Therefore, these findings highlight the advantages of the two-stage UASB system implemented, in which a high MPR and effective pollutant removal efficiency can be obtained.

\subsection{Effect of OLR increase on macro- and micronutrients proportion}

The proportion of the analyzed nutrients was found among the optimal values recommended for methanogenesis, obtaining a ratio of COD:N:P about 350:5:1, and proper concentrations of $\mathrm{Mg}$ and $\mathrm{Ca}$, with values ranged from 1.0 to 2.4 and 0.52 to $1.41 \mathrm{mg}$ (mg $\left.\mathrm{COD}_{\text {removed }}\right)^{-1}$, respectively. The proportion of $\mathrm{Ca}$ was higher in the first operational phases (phases 1 and 2), favored by the application of lime for $\mathrm{pH}$ neutralization. Consequently, although the addition of this external source of alkalinity increases the operational cost, it provides a stimulatory concentration of $\mathrm{Ca}$ for anaerobic digestion.

Starting from the implementation of effluent recirculation (phase 3), the proportion of $\mathrm{Fe}$ and $\mathrm{Zn}$ was increased. These elements are key factors required in diverse anaerobic reactions involving hydrogenase and methane-monooxygenase activity, among others (Takashima et al., 2011). A gradual increase in the proportion of Fe was also observed during the experimental period (associated with the OLR increase), obtaining a proportion in phase 5 of 2.5 and $7.0 \mathrm{mg}(\mathrm{mg} \mathrm{COD} \text { removed })^{-1}$ for R1 and R2 respectively. These values were in optimal theoretical levels according to Wu et al. (2016) (1.1 to $30.1 \mathrm{mg}$ Fe (mg CO$\left.\mathrm{D}_{\text {removed }}\right)^{-1}$ ).

Fe can decrease the oxidative-reductive potential in the medium, generating proper environmental conditions for anaerobic digestion. Besides, it is a key cofactor of enzymatic activities of methanogens, such as Fe-only hydrogenases (Pelletier et al., 2008) and pyruvate-ferredoxin oxidoreductase (Romero-Güiza et al., 2016). Previous studies have shown that supplementation of Fe during the anaerobic treatment of a variety of effluents plays a prominent role in the system efficiency, increasing the conversion rate of organic volatile acids to methane (Barros et al., 2017; Yamada et al., 2015). Thus, the increase of Fe at high OLR evidenced in the present study is consistent with the stability and the high MPR obtained.

The requirements of micronutrients in the anaerobic digestion are highly variable. Therefore, additional studies are still needed to limit the optimal ranges of these compounds in order to enhance the anaerobic treatment of CPW. However, the operational conditions applied in this study, such as gradual increase of OLR and effluent recirculation constituted important strategies to obtain values close to the optimal nutrient levels to improve the performance of UASB reactor.

\subsection{Biomass concentration in UASB reactors}

The highest biomass concentration in the UASB reactors, expressed as grams of volatile solids per litters of sludge $\left(\mathrm{g} \mathrm{VS} \mathrm{L}^{-1}\right)$, was observed in the bottom level of $\mathrm{R} 1$, reaching mean values between 20 and $103.6 \mathrm{~g} \mathrm{~L}^{-1}$. With the increment of the OLR to $10.1 \mathrm{~g} \mathrm{COD}(\mathrm{L} \mathrm{d})^{-1}(\mathrm{R} 1)$

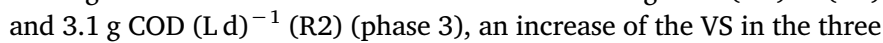
sludge collection points of both reactors was obtained. This may be related to a major availability of substrate for microbial growth. In addition, the levels of sludge loading rate (SLR) ranged from 0.15 to $0.26 \mathrm{~g} \mathrm{COD}(\mathrm{g} \mathrm{VS} \mathrm{d})^{-1}$ and 0.09-0.37 $\mathrm{g} \mathrm{COD}(\mathrm{g} \mathrm{VS} \mathrm{d})^{-1}$ in R1 and R2, respectively (Table 1 ). Chernicharo (2007) cited that in the anaerobic treatment of domestic wastewater it is recommended a SLR between 0.1 and $0.4 \mathrm{~g} \mathrm{COD}(\mathrm{g} \mathrm{VS} \mathrm{d})^{-1}$. In this study, the SLR was maintained in the acceptable levels in R1 throughout the experimental period, and in R2 from phase 3. Consequently, these conditions are consistent with the highest removals of COD obtained for both reactors in phase 3 , and facilitate higher methane production in both reactors at higher OLRs. The major concentration of biomass in R1 is linked with the highest efficiency. Besides, R1 has the highest HRT and compounds of the substrate may afford significant energy for microbial metabolism.

In phases 4 and 5 , the concentration of VS in the digestion compartment of both UASB reactors showed a decrease, particularly due to the application of lowers HRTs. During phases 4 and 5, due to decrease of HRT, the increased flow of influent lead to wash out of light sludge, which may be the main reason to sludge decreasing. This could explain the VS increment in the final effluent at high OLR (Table 2). Despite this physical limitation, biomass concentration in the three sludge collection points analyzed in both reactors showed constant levels after 330 days of operation, and sludge development evidenced during the experimental period allowed the generation and maintenance of an adapted microbiota to the conditions imposed, contributing to a better performance and stability of the reactors.

\subsection{Microbial community composition of R1}

\subsubsection{Next generation sequencing analyses}

The composition of the microbial community associated with the sludge of R1 was determined at low and high OLR conditions (6.1 and $18.2 \mathrm{~g} \mathrm{COD}(\mathrm{L} \mathrm{d})^{-1}$, respectively). This reactor was selected as it was submitted to higher organic load variation, showing a stable performance and the higher MPR and COD removal. At domain level, the majority of reads were assigned to Bacteria (Fig. 4a), which can be explained by the high growth rate and wide metabolic versatility of these microorganisms. Archaeal reads were accounted for a high proportion at low OLR. The Eukaryota and Viruses did not represent above
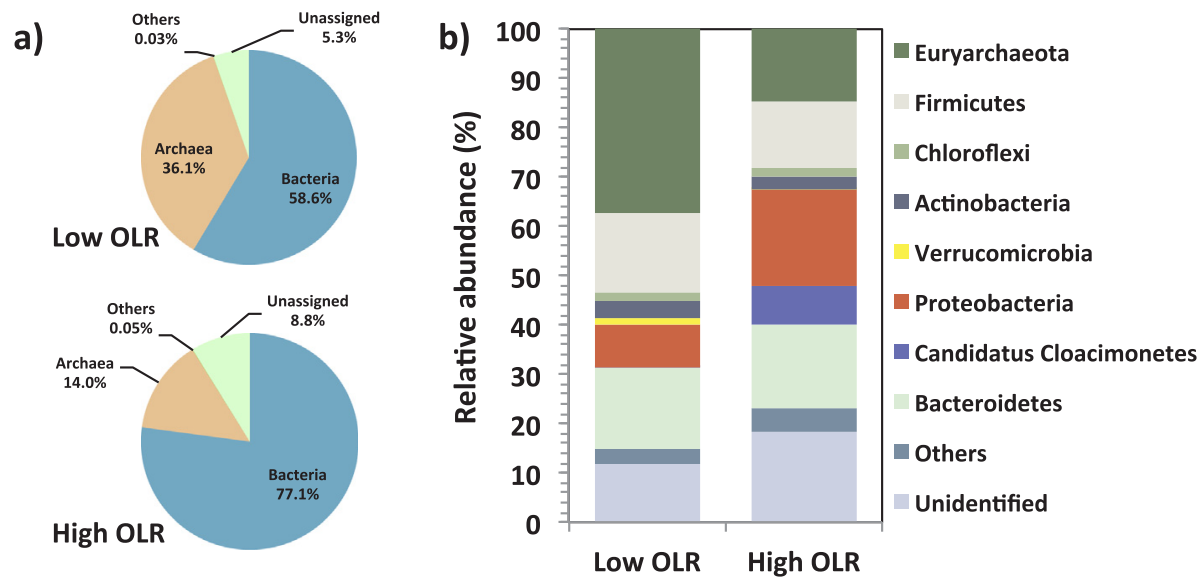

Fig. 4. Taxonomic distribution at domain (a) and at phylum level (b) in R1 for low and high OLR (6.1-18.2 g COD (L d) ${ }^{-1}$, respectively). Others: taxa with $<1 \%$ of the total composition. 
$0.05 \%$ of relative abundance for the analyzed conditions.

The high OLR condition presented a low diversity and a high dominance of Bacteria and Archaea populations, which suggest that the shift of operational conditions led to the selection of a more specific microbiome. This was additionally influenced by the influent composition, which showed increasing concentrations of VFAs, COD, TPC and nitrogen compounds from low to high OLR (Table 2, phases 1 and 5). Therefore, the high performance evidenced in terms of methane production and removal efficiency of organic matter and other constituents, suggest that prevalent microorganisms highly adapted to the imposed conditions participated actively in the anaerobic digestion of CPW.

The taxonomic distribution of the phylum Proteobacteria increased from low to high OLR (Fig. 4b). The dominant genus detected in this division was Syntrophus, increasing about 58\% from low to high OLR Syntrophus produce $\mathrm{H}_{2}$ via fermentation of diverse organic compounds, being able to establish syntrophic interactions with hydrogenotrophic methanogens (McInerney et al., 2007). A large part of the energy requirements of this bacterium derive from the degradation of organic acids (McInerney et al., 2007). In fact, its prevalence has been documented in reactors operated at high concentrations of VFAs (Gulhane et al., 2017), which is consistent with the results obtained in the present study. An additional role of Syntrophus in the anaerobic digestion of CPW could be associated with the anaerobic degradation of phenol via benzoate to form acetate and $\mathrm{H}_{2}$ (Fang et al., 2006), which subsequently may be used by acetotrophic and hydrogenotrophic methanogens.

The phylum candidate Cloacimonetes represented by Candidatus Cloacimonas showed a marked increase at high OLR (Fig. 4b), with a relative abundance of $14.2 \%$, being practically undetectable at low OLR. This bacterium derives most of its carbon and energy from the fermentation of amino acids (Pelletier et al., 2008). In addition, it cannot produce polyamines, several cofactors and amino acids, which must be obtained from the environment. Therefore, its prevalence could be associated with a higher availability of organic nitrogen, since the concentration of these compounds in the influent of the UASB reactor increased up to twice from low to high OLR (Table 2).

Candidatus Cloacimonas can oxidize propionate as well as to produce $\mathrm{H}_{2}$ by fermentation or via Fe-only hydrogenases (Pelletier et al., 2008), establishing syntrophic interactions with hydrogen utilizers. Thus, its increase at high OLR is consistent with the abundance of hydrogenotrophic methanogens in this condition (Fig. 5b).

Since its different nutritional requirements and the increased substrate availability for both, the interaction between Candidatus Cloacimonas and Syntrophus was not competitive. Consequently, this condition stimulated the development of hydrogenotrophic

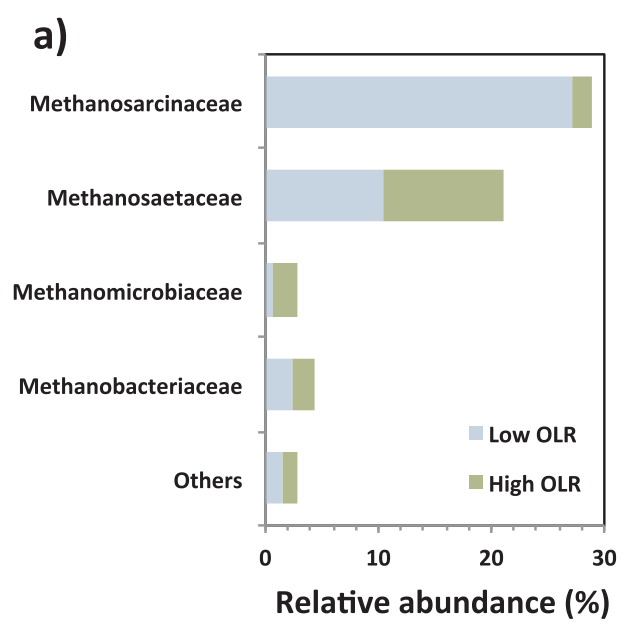

methanogenesis that maintained a low hydrogen pressure, which allowed a stable operation of the UASB reactor with high methane production.

Despite the shift of the OLR, the phyla Bacteroidetes, Actinobacteria, Chloroflexi and Firmicutes do not present a significant abundance alteration (Fig. 5b). These divisions included genus like Bacteroides, Propionibacterium, Clostridium, Longilinea and Sedimentibacter, which presents a wide range of metabolic characteristics, such as break down of complex organic compounds, fermentation of sugars, amino-acids metabolism and syntrophic sulphate-reducing activity among others (Enzmann et al., 2018). Consequently, since its similar abundance during the overall anaerobic digestion of CPW, these microorganisms are part of the core microbiome necessary for the proper reactor performance in the CPW treatment.

The phylum Euryarchaeota decreased about 50\% with the OLR, and showed a high abundance of the families Methanosarcinaceae and Methanosaetaceae (Fig. 5a). Considering that in these conditions the higher methane production rates were obtained (Fig. 2a), the stable performance of the anaerobic reactor can be explained by the different microbial profile evidenced, which presented a high abundance of syntrophic bacteria, generating proper thermodynamic conditions for the methanogens activity. The genus Methanosarcina presented the higher abundance at low OLR, whereas Methanosaeta was relevant at high OLR (Fig. 5b). This observation has been evidenced in other anaerobic systems treating high-strength wastewater, and could be attributed to a lower affinity of Methanosarcina to form or incorporate into the anaerobic granules in contrast to Methanosaeta (van Haandel et al., 2014).

The hydrogenotrophic genera Methanoculleus, Methanobacterium, Methanomassiliicoccus and Methanospirillum presented high abundance at high OLR (Fig. 5b), suggesting that a wide distribution of both acetoclastic and hydrogenotrophic methanogens is involved into the anaerobic digestion of CPW at high OLR, producing high levels of methane from acetic acid, $\mathrm{H}_{2}$ and $\mathrm{CO}_{2}$.

\subsubsection{Real-time $q P C R$}

Relevant microbial groups detected by next-generation sequencing were quantified by qPCR from sludge samples of bottom, middle and top levels of the digestion compartment of R1 at low and high OLR. Fig. 6 shows that Bacteria predominated in the three levels, presenting the higher abundance at high OLR (ranging from $1.2 \times 10^{13}$ to $1.4 \times 10^{12}$ copies of $16 \mathrm{~S}$ rDNA genes from bottom to top level). These values represent an increase of 2.5 folds in relation to low OLR, which is attributed to the high substrate availability in the influent. Therefore, bacterial populations quickly consumed the substrate and achieved a higher conversion of organic matter producing acetic acid, $\mathrm{H}_{2}$ and $\mathrm{CO}_{2}$ b)
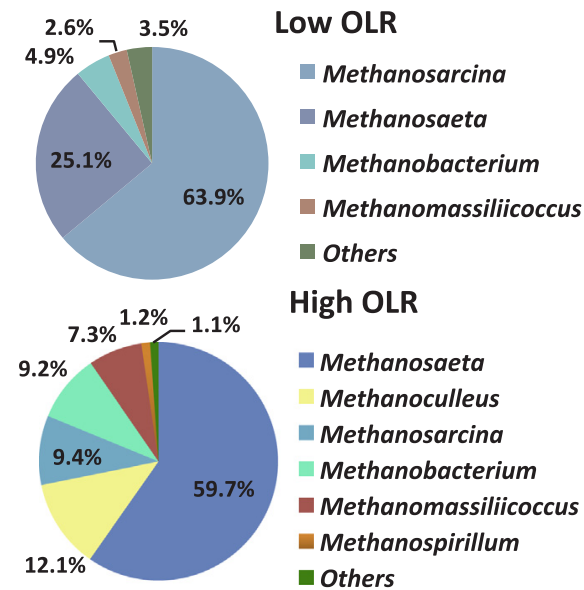

High OLR

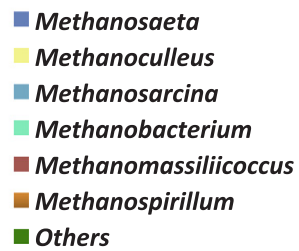

Fig. 5. Abundance of Archaea domain in R1 at class (a) and genera (b) levels. Low and High OLR: 6.1 and 18.2 g COD (L d) ${ }^{-1}$, respectively. 
UASB R1

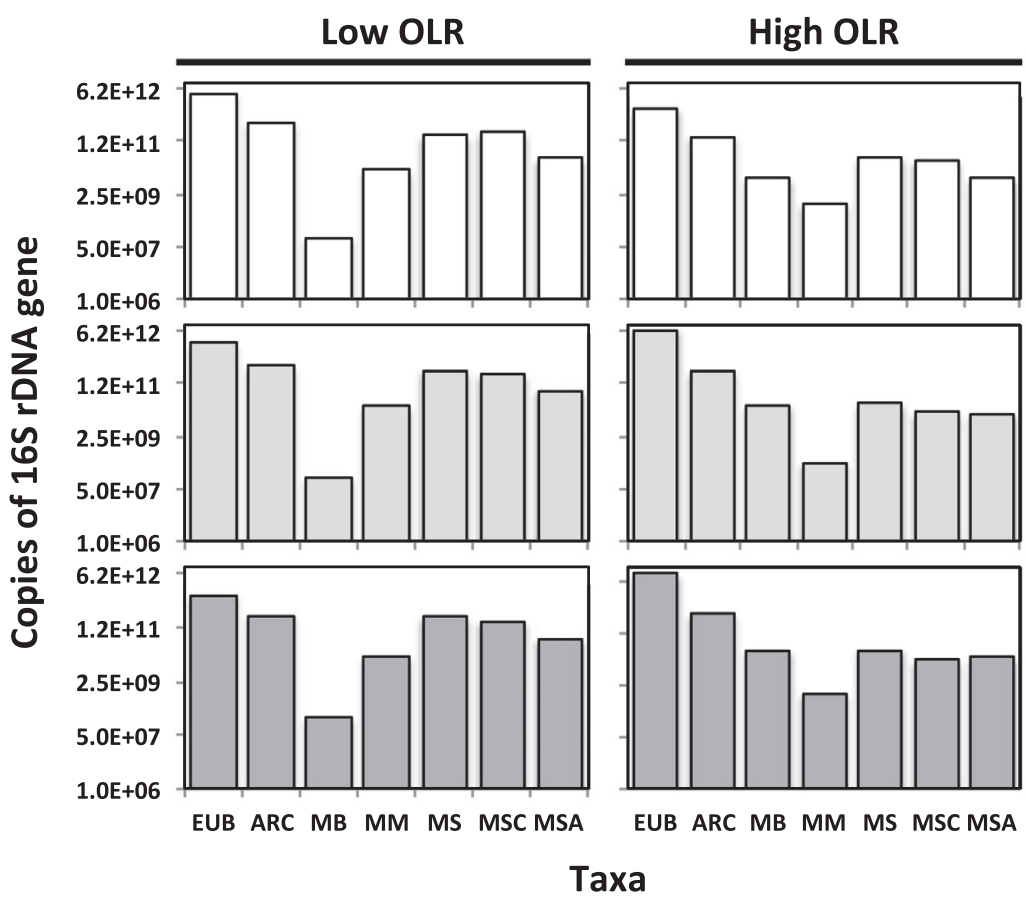

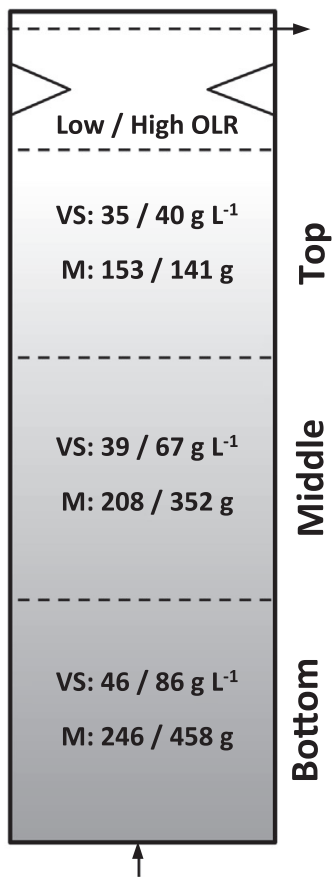

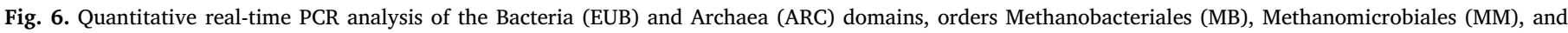

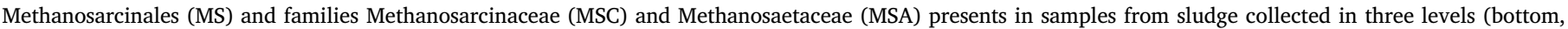
middle and top) of R1 at 90 (Low OLR) and 335 (High OLR) days of operation. SV: Volatile solids concentration; M: Amount of biomass.

for methanogenesis.

Despite the shift of the operational conditions, the relative abundance of Archaea populations tended to be constant (Fig. 6). The proportion of Archaea to the total microbe amount can vary according to the substrate characteristics and system conditions. Although values between 5 and 10\% have been reported (Cai et al., 2016), studies of anaerobic digestion of high-strength wastewater have evidenced values as high as 22\% (Barros et al., 2017; Duda et al., 2015). In this study, we obtained a high proportion of Archaea, evidencing up to $20 \%$ and $11 \%$ at low and high OLR, respectively. The quantities of Archaea detected in $\mathrm{R} 1$ even at high OLR are in consonance with the levels of methane output (Fig. 2b) and COD removal (Fig. 2a). Therefore, the stable performance of this reactor depends on the balance between these domains, regardless of their biokinetic and environmental requirement differences.

The predominance of Methanosarcinaceae at low OLR (Fig. 6) indicates that in these conditions the methane production is carried out mainly by acetoclastic methanogenesis. With the OLR increase, a high abundance of Methanosarcinales and similar 16S rRNA gene copies of the families Methanosarcinaceae and Methanosaetaceae were observed. Members of Methanosarcinaceae are metabolically versatile (able to use $\mathrm{H}_{2}-\mathrm{CO}_{2}$, acetate and methyl compounds as substrate) (Liu and Whitman, 2008). Therefore, despite the variable conditions and high OLR applied on R1, the abundance of Methanosarcinaceae can be attributed to its mixotrophic metabolism. Similar absolute quantities of Methanosarcinaceae and Methanosaetaceae highlight the importance of both families for methane production from CPW.

The abundance of Methanosaetaceae at high OLR is an indicative of the development of the acetate pathway to methane production, and suggests adequate microenvironmental conditions for its development (i.e. presence of regions with low acetate concentrations into the reactor as occurs in the central region of anaerobic sludge granules) (Guiot et al., 1992). Information regarding the effect of VFAs on methanogens suggests that Methanosaetaceae can be dominant in anaerobic digestion systems with concentrations of acetic acid lower than $1000 \mathrm{mg} \mathrm{L}^{-1}$ (Karakashev et al., 2005). In this study, the mean value of total VFAs obtained in the effluent of R1 at high OLR was $758 \mathrm{mg} \mathrm{L}^{-1}$, which indicates that acetic acid concentration is even lower. Therefore, it is in agreement with the prevalence of Methanosaetaceae in the UASB reactor treating CPW under the imposed conditions.

A marked increase (up to three magnitude orders) of the hydrogenotrophic methanogens quantified (Methanobacteriales) was evidenced at high OLR. This condition can be explained mainly by the difference in the specific growth rate between acetoclastic and hydrogenotrophic methanogens. In addition, the increment of the metabolic activity of hydrogen producing syntrophic bacteria prevalent at high OLR, with the relative abundance of Syntrophus and Candidatus Cloacimonas, provided fair conditions to interspecies hydrogen transfer, enabling the increase of hydrogenotrophic methanogens, mainly Methanobacterium and Methanoculleus (Fig. 5b).

The important fraction of hydrogenotrophic methanogens present in R1 provided stability conditions during the $\mathrm{CPW}$, favoring the methane production. This observation is supported by previous studies, which reported a change from acetoclastic to hydrogenotrophic pathway, or the relevance of hydrogenotrophic methanogens, mainly of the order Methanobacteriales, at high organic load during the anaerobic digestion of high-strength wastewaters, although operating conditions and substrate were different from this study (Barros et al., 2017; Duda et al., 2015; Jang et al., 2014). This was consistent with the hydrogenotrophic profile obtained at high OLR, which showed a predominance of Methanobacteriales.

Our results suggest that the high methane production in R1, (MPR of $2.2 \mathrm{~L} \mathrm{CH}_{4}(\mathrm{~L} \mathrm{~d})^{-1}$ at OLR of $18.2 \mathrm{~g} \mathrm{COD}(\mathrm{L} \mathrm{d})^{-1}$ ), depended on the high relative abundance of highly specialist bacteria, mainly syntrophic groups, and balanced co-existence between hydrogenotrophic and 
acetotrophic methanogens in the digestion compartment. This condition, associated with the optimal levels of SLR, suggest proper conditions for the anaerobic digestion and operational stability at high OLR, which allows a high efficiency for methane generation during the CPW treatment.

\section{Conclusions}

A system composed by two UASB reactors in series was effective for treating coffee processing wastewater at increasing organic loading rates (OLRs), maintaining a high methane production with suitable organic matter and phenols removal. These conditions were favored by the operation of the second-stage reactor, effluent recirculation, proportion of nutrients (particularly increase of $\mathrm{Fe}$ ) and sludge development. Under high OLR and steady operation, the molecular analysis revealed a reduction of the microbial diversity, with predominance of specialist microorganisms represented by syntrophic bacteria (Syntrophus and Candidatus Cloacimonas), and acetoclastic and hydrogenotrophic methanogens, mainly Methanosaeta and Methanoculleus.

\section{Acknowledgements}

We thank the Coordination for the Improvement of Higher Education Personnel (CAPES; Process $n^{\circ}$ PNPD-3137/2010) and the National Council for Scientific and Technological Development (CNPq; Process $n^{\circ} 483118 / 2011-7$ and 456426/2014-0) for financial support and CAPES for the scholarship of the first two authors.

\section{Appendix A. Supplementary data}

Supplementary data associated with this article can be found, in the online version, at https://doi.org/10.1016/j.biortech.2018.06.091.

\section{References}

Alves, R., Rodrigues, F., Nunes, M.A., 2017. State of the art in coffee processing byproducts. In: Galanakis, C. (Ed.), Handbook of Coffee Processing By-products. Academic press, London, pp. 1-22.

APHA, 2005. Standard Methods for the Examination of Water and Wastewater, 21st ed. American Public Health Association, Washington DC.

Barros, V.G., Duda, R.M., Vantini, J.D.S., Omori, W.P., Ferro, M.I.T., Oliveira, R.A., 2017 Improved methane production from sugarcane vinasse with filter cake in thermophilic UASB reactors, with predominance of Methanothermobacter and Methanosarcina archaea and Thermotogae bacteria. Bioresour. Technol. 244, 371-381.

Beyene, A., Yemane, D., Addis, T., Assayie, A.A., Triest, L., 2014. Experimental evaluation of anaerobic digestion for coffee wastewater treatment and its biomethane recovery potential. Int. J. Environ. Sci. Technol. 11, 1881-1886.

Bruno, M., de Oliveira, R.A., 2013. Performance of UASB reactors in two stages followed by post-treatment with activated sludge in wastewater batch of wet-processed coffee. Eng. Agric. 33, 808-819.

Cai, M., Wilkins, D., Chen, J., Ng, S.-K., Lu, H., Jia, Y., Lee, P.K.H., 2016. Metagenomic reconstruction of key anaerobic digestion pathways in municipal sludge and industrial wastewater biogas-producing systems. Front. Microbiol. 7, 1-12.

Chen, Y., Cheng, J.J., Creamer, K.S., 2008. Inhibition of anaerobic digestion process: a review. Bioresour. Technol, 99, 4044-4064.

Chernicharo, C.A.de L., 2007. Anaerobic Reactors. IWA Publishing, London.

Cruz-Salomón, A., Ríos-Valdovinos, E., Pola-Albores, F., Lagunas-Rivera, S., MezaGordillo, R., Ruíz-Valdiviezo, V.M., 2017. Evaluation of hydraulic retention time on treatment of coffee processing wastewater (CPWW) in EGSB bioreactor. Sustain 10,83 .

Delforno, T.P., Lacerda Jr., G.V., Sierra-Garcia, I.N., Okada, D.Y., Macedo, T.Z., Varesche, M.B.A., Oliveira, V.M., 2017. Metagenomic analysis of the microbiome in three different bioreactor configurations applied to commercial laundry wastewater treatment. Sci. Total Environ. 587-588, 389-398.

DiLallo, R., Albertson, O.E., 1961. Volatile acids by direct titration. Water Pollut. Control Fed. 33, 356-365.

Duda, R.M., Vantini, J.D.S., Martins, L.S., Varani, A.D.M., Lemos, M.V.F., Ferro, M.I.T., Oliveira, R.A. De, 2015. A balanced microbiota efficiently produces methane in a novel high-rate horizontal anaerobic reactor for the treatment of swine wastewater. Bioresour. Technol. 197, 152-160.

Enzmann, F., Mayer, F., Rother, M., Holtmann, D., 2018. Methanogens: biochemical background and biotechnological applications. AMB Express 8, 1-22.

Fang, H.H.P., Liang, D.W., Zhang, T., Liu, Y., 2006. Anaerobic treatment of phenol in wastewater under thermophilic condition. Water Res. 40, 427-434.

FAO, 2015. Statistical Pocketbook Coffee 2015. Food and Agriculture Organization of the
United Nations, Rome.

Fia, F.R.L., Matos, A.T., Borges, A.C., Fia, R., Cecon, P.R., 2012. Treatment of wastewater from coffee bean processing in anaerobic fixed bed reactors with different support materials: performance and kinetic modeling. J. Environ. Manage. 108, 14-21.

Guardia-Puebla, Y., Rodríguez-Pérez, S., Jiménez-Hernández, J., Sánchez-Girón, V., Morgan-Sagastume, J., 2014. Experimental design technique is useful tool to compare anaerobic systems. Renew. Bioresour. 2, 1-12.

Guiot, S.R., Pauss, A., Costerton, J.W., 1992. A structured model of the anaerobic granule consortium. Water Sci. Technol. 25, 1-10.

Gulhane, M., Pandit, P., Khardenavis, A., Singh, D., Purohit, H., 2017. Study of microbial community plasticity for anaerobic digestion of vegetable waste in Anaerobic Baffled Reactor. Renew. Energy 101, 59-66.

Hosni, K., Moussa, S. Ben, Chachi, A., Amor, M. Ben, 2008. The removal of $\mathrm{PO}_{4}$ by calcium hydroxide from synthetic wastewater: optimisation of the operating conditions. Desalination 223, 337-343.

Huson, D., Auch, A., Qi, J., Schuster, S., 2007. MEGAN analysis of metagenome data. Genome Res. 17, 377-386.

ICO, 2018. Trade Statistics [WWW Document]. URL http://www.ico.org/prices/po-production.pdf (accessed 1.13.18).

Jang, H.M., Kim, J.H., Ha, J.H., Park, J.M., 2014. Bacterial and methanogenic archaeal communities during the single-stage anaerobic digestion of high-strength food wastewater. Bioresour. Technol. 165, 174-182.

Jung, K.-W., Kim, D.-H., Lee, M.-Y., Shin, H.-S., 2012. Two-stage UASB reactor converting coffee drink manufacturing wastewater to hydrogen and methane. Int. J. Hydrogen Energy 37, 7473-7481.

Karakashev, D., Batstone, D.J., Angelidaki, I., 2005. Influence of environmental condi tions on methanogenic compositions in anaerobic biogas reactors. Appl. Environ. Microbiol. 71, 331-338.

Kim, J., Lim, J., Lee, C., 2013. Quantitative real-time PCR approaches for microbial community studies in wastewater treatment systems: applications and considerations. Biotechnol. Adv. 31, 1358-1373.

Lee, D.H., Zo, Y.G., Kim, S.J., 1996. Nonradioactive method to study genetic profiles of natural bacterial communities by PCR-single-strand conformation polymorphism. Appl. Environ. Microbiol. 62, 3112-3120.

Liu, Y., Whitman, W.B., 2008. Metabolic, phylogenetic, and ecological diversity of the methanogenic archaea. Ann. N. Y. Acad. Sci. 1125, 171-189.

McCarty, P.L., 1964. Anaerobic waste treatment fundamentals. Public Work 95, 107-112. McInerney, M.J., Rohlin, L., Mouttaki, H., Kim, U., Krupp, R.S., Rios-Hernandez, L. Sieber, J., Struchtemeyer, C.G., Bhattacharyya, A., Campbell, J.W., Gunsalus, R.P., 2007. The genome of Syntrophus aciditrophicus: life at the thermodynamic limit of microbial growth. Proc. Natl. Acad. Sci. 104, 7600-7605.

Niu, B., Zhu, Z., Fu, L., Wu, S., Li, W., 2011. FR-HIT, a very fast program to recruit metagenomic reads to homologous reference genomes. Bioinformatics 27, $1704-1705$.

Pelletier, E., Kreimeyer, A., Bocs, S., Rouy, Z., Gyapay, G., Chouari, R., Rivière, D., Ganesan, A., Daegelen, P., Sghir, A., Cohen, G.N., Médigue, C., Weissenbach, J., Le Paslier, D., 2008. "Candidatus Cloacamonas acidaminovorans": genome sequence reconstruction provides a first glimpse of a new bacterial division. J. Bacteriol. 190, 2572-2579.

Peng, Y., Leung, H.C.M., Yiu, S.M., Chin, F.Y.L., 2012. IDBA-UD: a de novo assembler for single-cell and metagenomic sequencing data with highly uneven depth. Bioinformatics 28, 1420-1428.

Pires, J.F., de Cardoso, L.S., Schwan, R.F., Silva, C.F., 2017. Diversity of microbiota found in coffee processing wastewater treatment plant. World J. Microbiol. Biotechnol. 33, 211.

Rattan, S., Parande, A.K., Nagaraju, V.D., Ghiwari, G.K., 2015. A comprehensive review on utilization of wastewater from coffee processing. Environ. Sci. Pollut. Res. 22, $6461-6472$.

Ripley, L.E., Boyle, W.C., Converse, J.C., 1986. Improved alkalimetric monitoring for anaerobic digestion of high-strength wastes. Water Pollut. Control Fed. 58, 406-411.

Romero-Güiza, M.S., Vila, J., Mata-Alvarez, J., Chimenos, J.M., Astals, S., 2016. The role of additives on anaerobic digestion: a review. Renew. Sustain. Energy Rev. 58, 1486-1499.

Scherer, P., Lippert, H., Wolff, G., 1983. Composition of the major elements and trace elements of 10 methanogenic bacteria determined by inductively coupled plasma emission spectrometry. Biol. Trace Elem. Res. 5, 149-163.

Selvamurugan, M., Doraisamy, P., Maheswari, M., 2010. An integrated treatment system for coffee processing wastewater using anaerobic and aerobic process. Ecol. Eng. 36, 1686-1690.

Singleton, V.L., Orthofer, R., Lamuela-Raventós, R.M., 1998. Analysis of total phenols and other oxidation substrates and antioxidants by means of Folin-Ciocalteu reagent. Methods Enzymol. 299, 152-178.

Song, M., Shin, S.G., Hwang, S., 2010. Methanogenic population dynamics assessed by real-time quantitative PCR in sludge granule in upflow anaerobic sludge blanket treating swine wastewater. Bioresour. Technol. 101, S23-S28.

Stams, A.J.M., Sousa, D.Z., Kleerebezem, R., Plugge, C.M., 2012. Role of syntrophic microbial communities in high-rate methanogenic bioreactors. Water Sci. Technol. 66 , 352-362.

Takashima, M., Shimada, K., Speece, R.E., 2011. Minimum requirements for trace metals (iron, nickel, cobalt, and zinc) in thermophilic and mesophilic methane fermentation from glucose. Water Environ. Res. 83, 339-346.

van Haandel, A., de Vrieze, J., Verstraete, W., dos Santos, V.S., 2014. Methanosaeta dominate acetoclastic methanogenesis during high-rate methane production in anaerobic reactors treating distillery wastewaters. J. Chem. Technol. Biotechnol. 89, $1751-1759$.

Villa-Montoya, A.C., Ferro, M.I.T., de Oliveira, R.A., 2017. Removal of phenols and 
methane production with coffee processing wastewater supplemented with phosphorous. Int. J. Environ. Sci. Technol. 14, 61-74.

Wirth, B., Krebs, M., Andert, J., 2015. Anaerobic degradation of increased phenol concentrations in batch assays. Environ. Sci. Pollut. Res. 22, 19048-19059.

Wu, L.J., Kobayashi, T., Kuramochi, H., Li, Y.Y., Xu, K.Q., 2016. Effects of potassium, magnesium, zinc, and manganese addition on the anaerobic digestion of de-oiled grease trap waste. Arab. J. Sci. Eng. 41, 2417-2427.

Yamada, C., Kato, S., Ueno, Y., Ishii, M., Igarashi, Y., 2015. Conductive iron oxides accelerate thermophilic methanogenesis from acetate and propionate. J. Biosci. Bioeng. $119,678-682$.

Yenigün, O., Demirel, B., 2013. Ammonia inhibition in anaerobic digestion: a review. Process Biochem. 48, 901-911. 